\title{
Correction to: Crohn's disease-specific mortality: a 30-year cohort study at a tertiary referral center in Japan
}

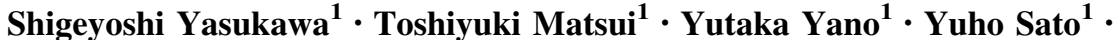 \\ Yasumichi Takada ${ }^{1} \cdot$ Masahiro Kishi $^{1} \cdot$ Yoichiro Ono $^{1} \cdot$ Noritaka Takatsu $^{1}$.

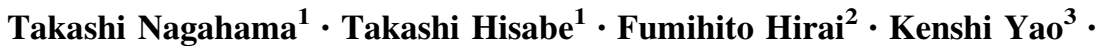 \\ Toshiharu Ueki $^{1}$ - Daijiro Higashi ${ }^{4} \cdot$ Kitaro Futami $^{4} \cdot$ Suketo Sou $^{5}$ • \\ Toshihiro Sakurai $^{6}$ - Tsuneyoshi Yao ${ }^{7}$ - Hiroshi Tanabe ${ }^{8}$. Akinori Iwashita ${ }^{8}$. \\ Masakazu Washio 9
}

Published online: 10 October 2021

(c) Japanese Society of Gastroenterology 2021

\section{Correction to: J Gastroenterol (2019) 54:42-52 https://doi.org/10.1007/s00535-018-1482-y}

The authors would like to correct in the publication of the original article. The correction details are given below for your reading.

The second sentence in the second paragraph under the heading "SMRs" on page 46 should be "SMRs were especially high for small intestinal cancer at 200 (95\% CI 34.6-806.7), CRC at 29.7 (95\% CI 16.5-53.7), and brain tumor at 12.5 (95\% CI 1.8-88.7)". The fourth sentence in the second paragraph under the "SMRs" on page 46-47 should be "However, high SMRs were not observed for many conditions, such as respiratory disease $(1.4 ; 95 \% \mathrm{CI}$ 0.4-5.7), cardiovascular disease $(1.3 ; 95 \%$ CI $0.4-3.9)$, suicide $(1.2 ; 95 \%$ CI $0.4-3.6)$, and traffic injuries $(0.7$; 95\% CI 0.1-5.1)".

In addition, the Table 3 was published with error. The corrected Table 3 is given in the following page.

The original article can be found online at https://doi.org/10.1007/ s00535-018-1482-y.

Toshiyuki Matsui

matsui@fukuoka-u.ac.jp

1 Department of Gastroenterology, Fukuoka University Chikushi Hospital, 1-1-1 Zokumyoin, Chikushino, Fukuoka 818-0067, Japan

2 Inflammatory Bowel Disease Center, Fukuoka University Chikushi Hospital, Fukuoka, Japan

3 Department of Endoscopy, Fukuoka University Chikushi Hospital, Fukuoka, Japan

4 Department of Surgery, Fukuoka University Chikushi Hospital, Fukuoka, Japan

5 Department of Gastroenterology, Tobata Kyoritsu Hospital, Kitakyushu, Japan
Department of Gastroenterology, Ashiya Central Hospital, Kitakyushu, Japan

7 Department of Gastroenterology, Sada Hospital, Fukuoka, Japan

8 Department of Pathology, Fukuoka University Chikushi Hospital, Fukuoka, Japan

9 Department of Community Health and Clinical Epidemiology, St. Mary's College, Kurume, Japan 
Table 3 All causes of death in Crohn's disease patients and standardized mortality ratios by cause of death

\begin{tabular}{|c|c|c|c|c|c|}
\hline Cause & ICD-10 code & Observed cases & Expected cases & SMR & $95 \% \mathrm{CI}$ \\
\hline All causes & & 52 & 14.8 & 3.5 & $2.7-4.6$ \\
\hline Malignant tumor & C00-D48 & 19 & 3.5 & 5.4 & $3.5-8.5$ \\
\hline Small intestinal cancer ${ }^{\mathrm{a}}$ & $\mathrm{C} 17$ & 2 & 0.01 & 200 & $34.6-806.7$ \\
\hline Colorectal cancer $^{\mathrm{a}}$ & $\mathrm{C} 18-\mathrm{C} 21$ & 11 & 0.37 & 29.7 & $16.5-53.7$ \\
\hline Lung cancer & $\mathrm{C} 33-\mathrm{C} 34$ & 2 & 0.45 & 4.4 & $1.1-17.8$ \\
\hline Lymphatic cancer & C81-C96 & 2 & 0.72 & 2.8 & $0.7-11.1$ \\
\hline Brain tumor & $\mathrm{C} 70-\mathrm{C} 72$ & 1 & 0.08 & 12.5 & $1.8-88.7$ \\
\hline Cancer of unknown primary & - & 1 & - & - & - \\
\hline Gastrointestinal disease $^{\mathrm{a}}$ (excluding K71-76) & K00-70, 77-93 & 15 & 0.31 & 48.4 & $29.2-80.3$ \\
\hline Non-alcoholic liver disease & K71-76 & 3 & 0.21 & 14.3 & $4.6-44.3$ \\
\hline Respiratory disease & J00-J99 & 2 & 1.4 & 1.4 & $0.4-5.7$ \\
\hline Cardiovascular disease & I00-I99 & 3 & 2.4 & 1.3 & $0.4-3.9$ \\
\hline Suicide & X60-X84 & 3 & 2.6 & 1.2 & $0.4-3.6$ \\
\hline Metabolic disease (amyloidosis) $^{a}$ & E85 & 5 & 0.005 & 1000 & $416.2-2402.6$ \\
\hline Traffic injuries & V00-V89 & 1 & 1.4 & 0.7 & $0.1-5.1$ \\
\hline Unknown & - & 1 & - & - & - \\
\hline CD-specific causes ${ }^{a}$ & & 33 & 0.9 & 36.7 & $26.1-51.6$ \\
\hline
\end{tabular}

ICD-10 International Classification of Diseases-10, SMR standardized mortality ratio, $C I$ confidence interval

${ }^{a} \mathrm{CD}$-specific causes are small bowel and colorectal cancer, gastrointestinal disease, and amyloidosis

Publisher's Note Springer Nature remains neutral with regard to jurisdictional claims in published maps and institutional affiliations. 